\title{
FORD/ERDA CONTINUOUSLY VARIABLE TRANSMISSION
}

PHASE I - TRANSMISSION DESIGN

Progress Report No. 6

For Period October 1-Decenber 31, 1975

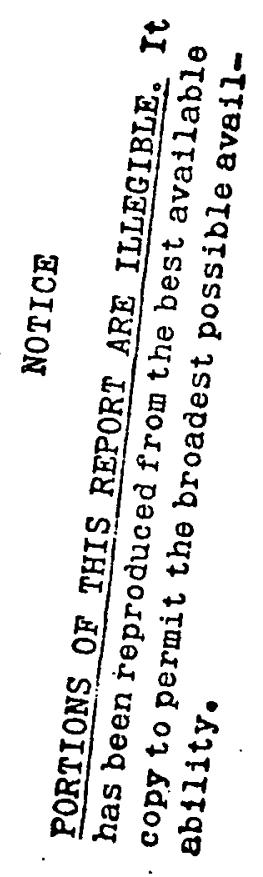

T. R. Stockton

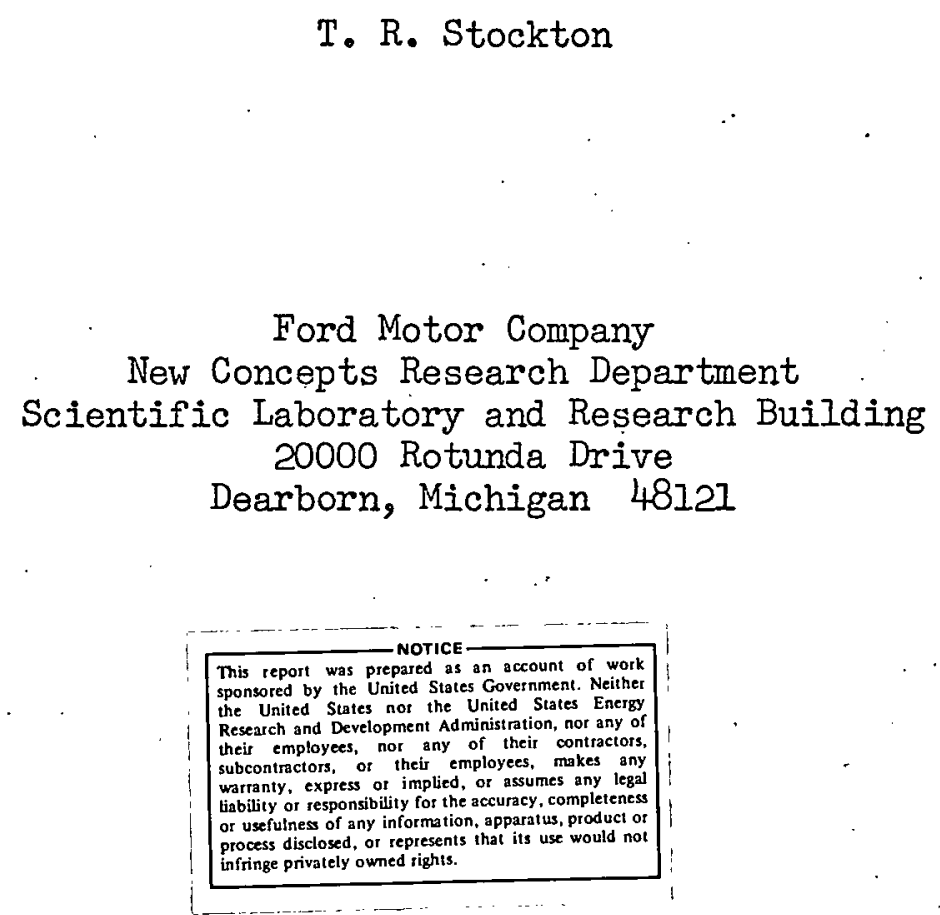

Prepared For

THE U. S. ENERGY RESEARCH AND DEVELOPMENT ADMINISTRATION

UNDER CONTRACT NO. E(11-1) -2674 


\section{DISCLAIMER}

This report was prepared as an account of work sponsored by an agency of the United States Government. Neither the United States Government nor any agency Thereof, nor any of their employees, makes any warranty, express or implied, or assumes any legal liability or responsibility for the accuracy, completeness, or usefulness of any information, apparatus, product, or process disclosed, or represents that its use would not infringe privately owned rights. Reference herein to any specific commercial product, process, or service by trade name, trademark, manufacturer, or otherwise does not necessarily constitute or imply its endorsement, recommendation, or favoring by the United States Government or any agency thereof. The views and opinions of authors expressed herein do not necessarily state or reflect those of the United States Government or any agency thereof. 


\section{DISCLAIMER}

Portions of this document may be illegible in electronic image products. Images are produced from the best available original document. 


$\frac{\text { FORD/PRDA CONTINUOUSLY VARIABLE TRANSMISSION }}{\frac{\text { FOR PERIOD OCTOBER I- DECEMBER 3I, } 1975}{\text { Contract E(11-1)-2674 }}}$

\section{A. Background}

Ford Motor Company has been continuously studying various types of Infinitely Variable (I.V.) Transmissions for improving passenger car fuel economy. To date, the Forster traction drive I.V. transmission appears attractive because it may simplify the complexity and reduce manufacturing costs associated with other traction drives by virtue of its ratio-changingmnechanism. Although the Forster concept is yet to be proven in hardware, the study justified a full engineering analysis. Contract $E(I I-1)-2674$ was awarded with an effective date of June 15, 1975, to evaluate the Forster concept.

\section{B. Objectives}

The primary objective of Contract $\mathrm{E}(11-1)-2674$ is to perform an analysis and design of the Forster concept, providing ERDA with an over-all transmission design layout including controls and test data on the traction drive components.

\section{Progress to Date}

The program plan of Attachment I. gives a general overview of the program status. The four basic areas of concerm: design analysis, performance and fuel economy analysis, transmission layout, and test rig evaluation of the traction mechanism w: 11 be commented on.

Design Analysis:

The bulk of the analytical design work has been confined to the traction drive mechanism. The conventional transmission components, such as torque converters, gear trains, etc., have been sized for the application. A more detailed analysis will follow as conventional components become fixed.

The traction drive mechanism under investigation embodies flexible torus discs"pressing. against spherical rollers. speed ratio across the mechanism will be varied by modulating the disc contour with hydraulic control pressure.

The data for the analytical program of the traction mechanism was updated, using new data-generating programs, and additional information on traction coefficient. Traction coefficient varies with contact velocity and compressive stresses due to contact forces. The computer program with updated data was used to establish the newest flexible disc design. The disc dimensions are as follows:

Contour Radius Disc Thickness Outside Diameter Inside Diameter Pitch Diameter

$\begin{array}{ll}- & 2.9^{\prime \prime} \\ - & .170^{\prime \prime} \\ - & 7 \cdot 9^{\prime \prime} \\ - & 2 \cdot 5^{\prime \prime} \\ - & 2.6^{\prime \prime}\end{array}$


The maximum combined stress was about 121,400 psi at the most underdrive position (severest service condition) where the total axial load is highest at 15,500 lbs. Disc contour radii and thickness will be varied and investigated further. Also, new methods of predicting the elastic shape of the disc in the deflected condition are being investigated because of the need of greater accuracy.

Performance and Fuel Economy Analysis:

Ford computer program has been modified to predict $I . V$. transmission W.O.T. acceleration performance for the original I.V. configuration which placed the torque converter between the engine and the I.V. unit. Program modification has been initiated to incorporate the new I.V. configurations which place the I.V. unit between the engine and the torque converter.

A computer model has been developed which calculates steady state fuel economies for the new I.V. configuration. At present, it assumes constant I.V. unit efficiency regardless of load and speed ratios. It requires modifications to incorporate variable I.V. unit efficiency for CVS and EPA highway cycles.

Transmission Layout:

Attachment II illustrates the schematic of the original "Forster Transmission" (Schematic I) and the latest Ford proposal (Schematic II), Several changes were made in going from the originai concept to the present:

- A torque converter was utilized rather than a fluid coupling. This reduces the speed ratio range required of the traction unit, consequently resulting in lower bending stresses in the flex plates.

- The "step-up" gear set ahead of the traction device was eliminated. This results in lower operating speed for the input and output flex plates. Experimental data indicate that reducing the rolling velocity results in an increase in the coefficient of traction. This reduction in speed with a lessthan-proportional increase in required thrust load may allow the use of roller thrust bearings.

- The traction device was positioned "upstream" of the converter in the power flow in order to eliminate the need for lock-up originally planned. A large converter is required to transmit the high torque at low speed in the underdrive acceleration mode. This large converter is very efficient in the overdrive cruise mode of operation. 
- The gear set is used only for reverse. This type of planetary gear set can be designed so as to give the same ratio in reverse as in the forward mode. Reverse and low gear ratio are typically nearly equal. The gear set is locked up in all forward speeds so as to reduce losses and increase gear life. The number of friction elements has been reduced from six to two.

Attachment III illustrates the preliminary layout of the new schematic (Ford).

\section{Test Rig:}

The test rig design, detailing, checking, and ordering have been completed. All of the rig parts are scheduled to be ready for assembly by the third week in January. The test rig is illustrated in Attachment IV.

A set of solid (non-flexing) discs has been designed to fit into the test rig. The purpose of solid disc testing is to determine the coefficient of traction and losses corresponding to various combinations of curvature. This information can then be used to accurately predict the performance of the flex plate design.

Attachment $V$ illustrates the solid discs as assembled in the test rig.

D, Meetings

Met with ERDA representative, Bob Kost, November 3, 1975, to discuss progress to date.

Contractors' Co-Ordination Meeting was held at Ann Arbor, Michigan, on November 18, 1975...

E. Communications

The following communications were issued during this period:

- Quarterly Progress Report No. 3 for Reporting Period July 1 - September 30, 1975.

- Prepared a Project Sumary Presentation for the ERDA, November 18, 1975, Contractors: Co-Ordination Meeting.

- Monthly Progress Report No. 4 for Reporiing Period October 1 - October 31, 1975.

- Monthly Progress Report No. 5 for Reporting Period November 1 - November 30, 1975. 
F. Financial Status

Contract Cost, Excluding Fee

$\$ 370,920.00$

Incurred Cost, through December 31, $1975 \quad 166,600.00$

Balance as of December 31, $1975 \quad \$ 204,320.00$ 
TORD/ARDA CONMTNUOUSLY VARTAZTT TTRANSMISSTON STUDY

FORD/ERDA CONGNTRAT NO. $E(21-2)-2674$

NON-CONGTDENTIAI,

\section{PROGRAM ELANT}

C. $1975 \mid 1976$

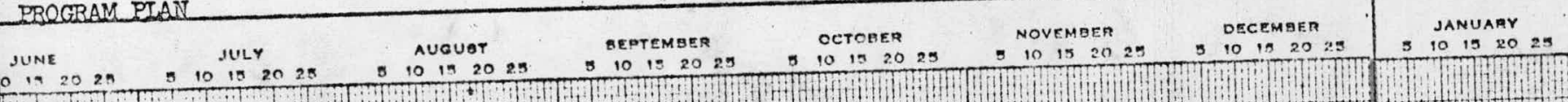

FEDRUARY MAPCH

PHASE I CONTRACT COMPLETION
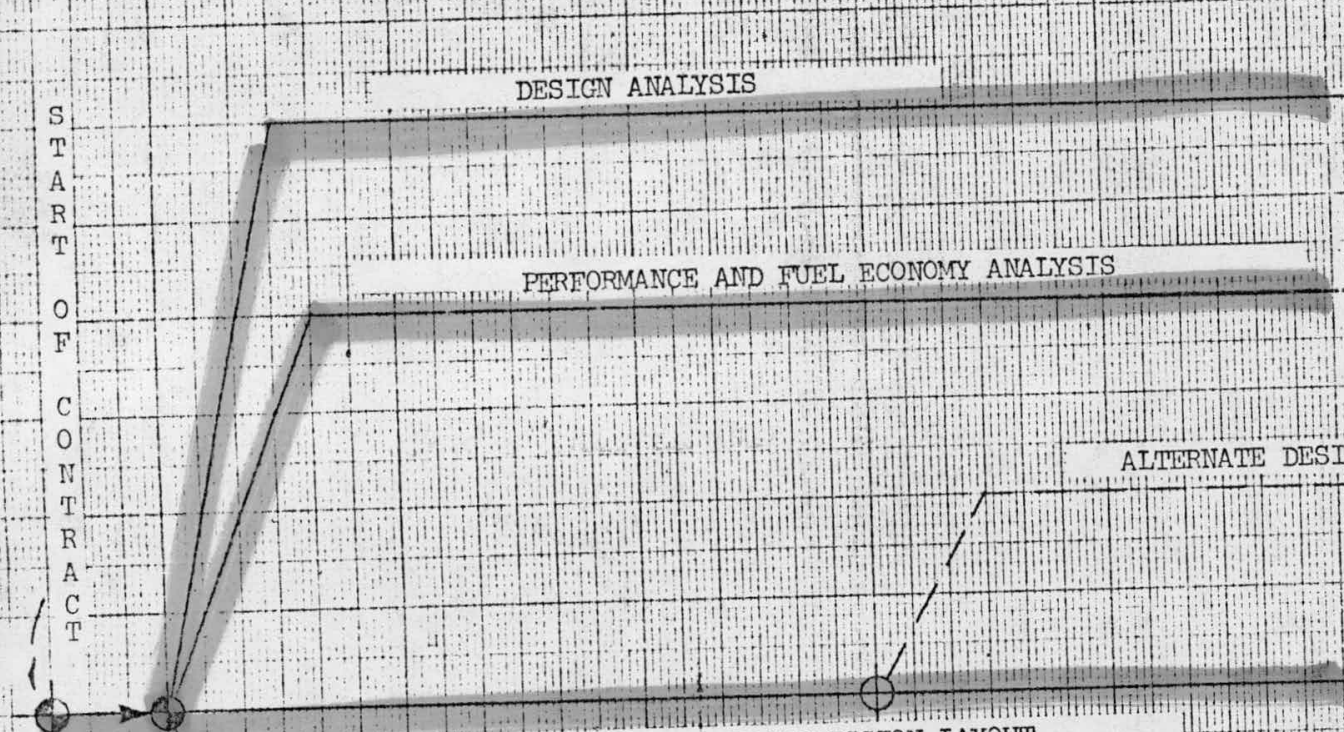
TRANSMISSION LAYOUT

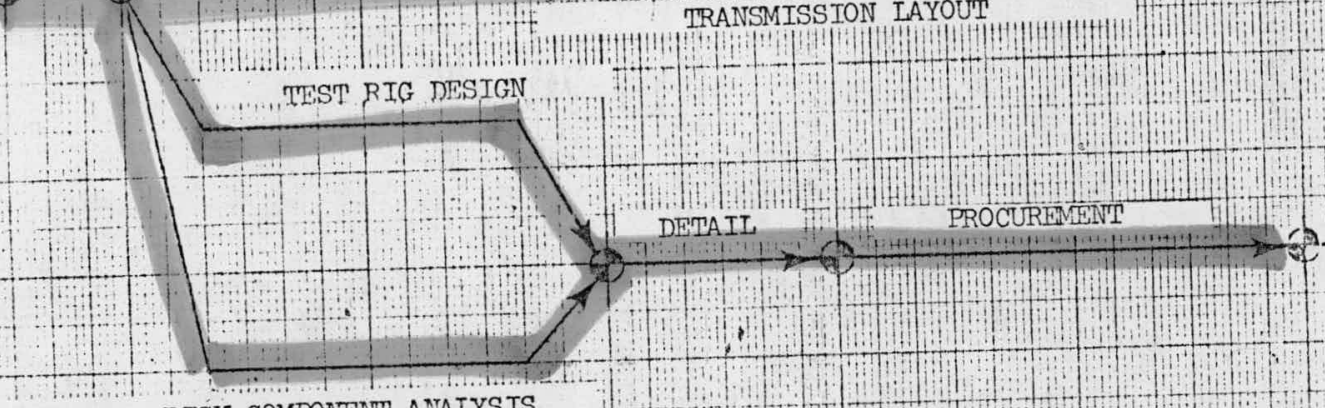

HIGH RISK COMPONENI ANAIYSIS

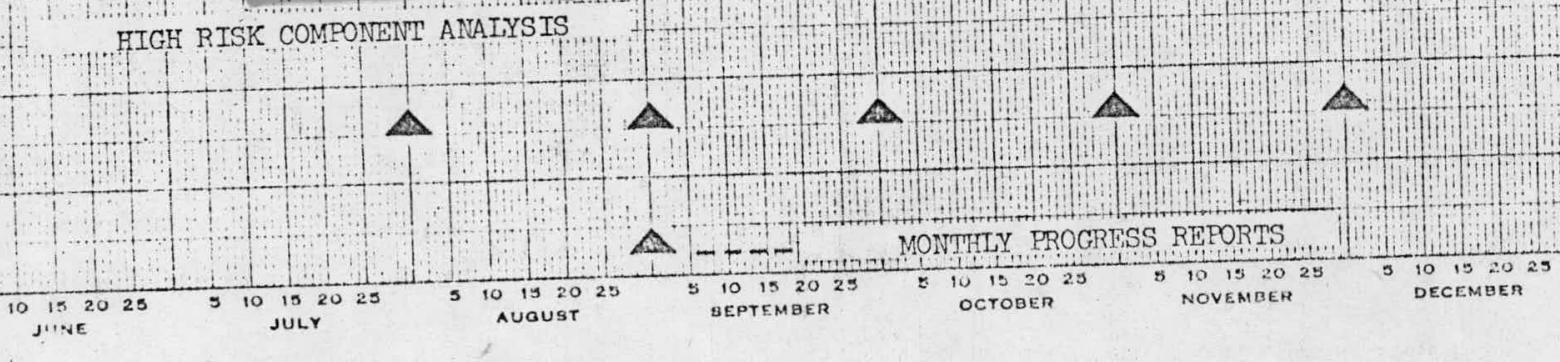

TEST EVALUATION
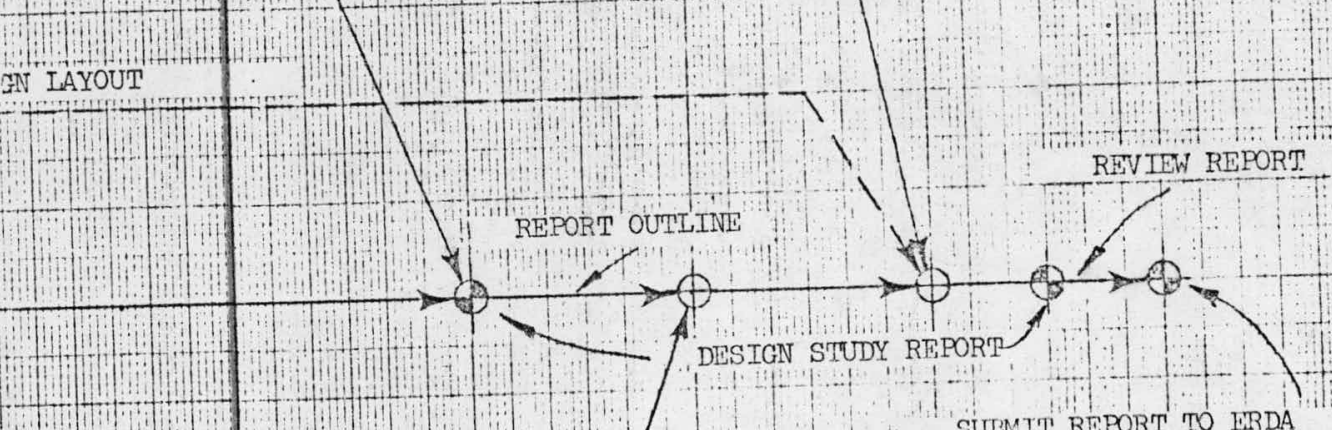

SUTMTT REPORT TO ERDA

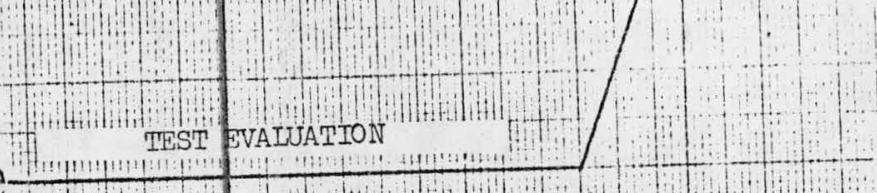

$1+1101$ 


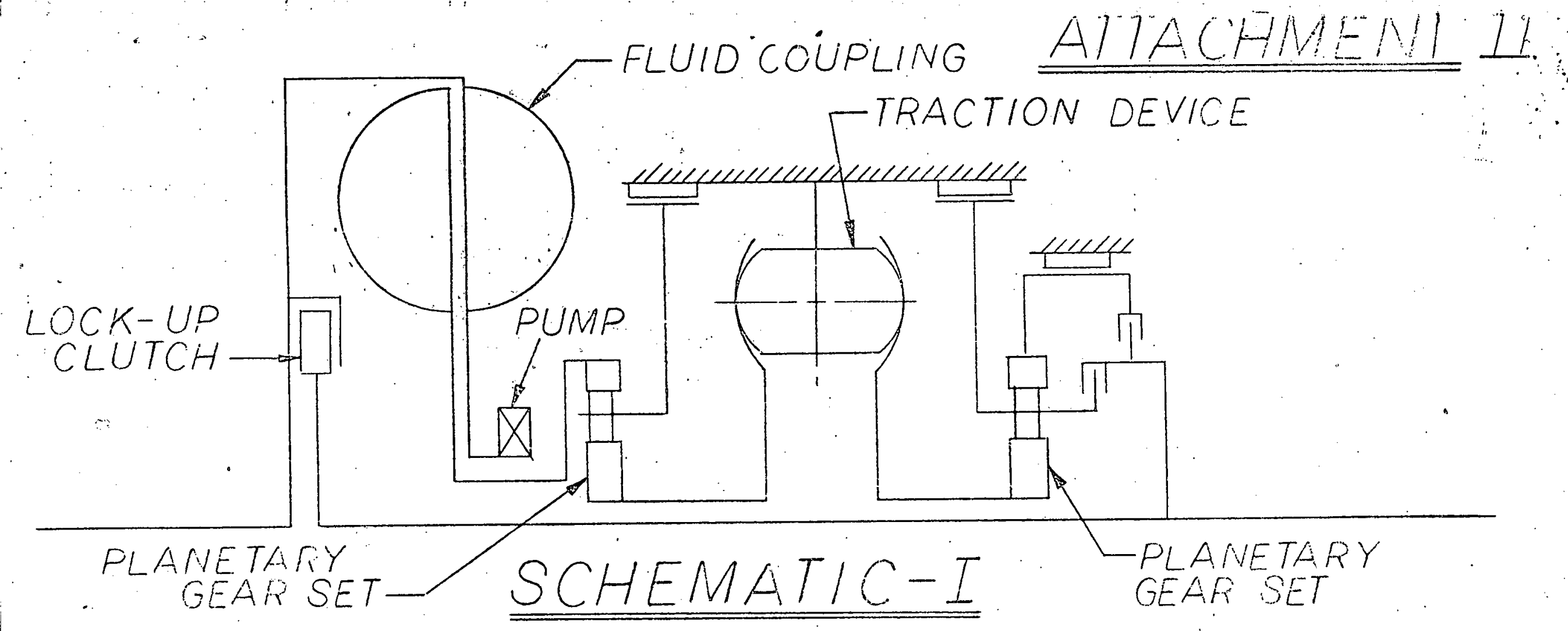

TORQUE CONVERTER7 $\therefore$ TTRACTION DEVICE

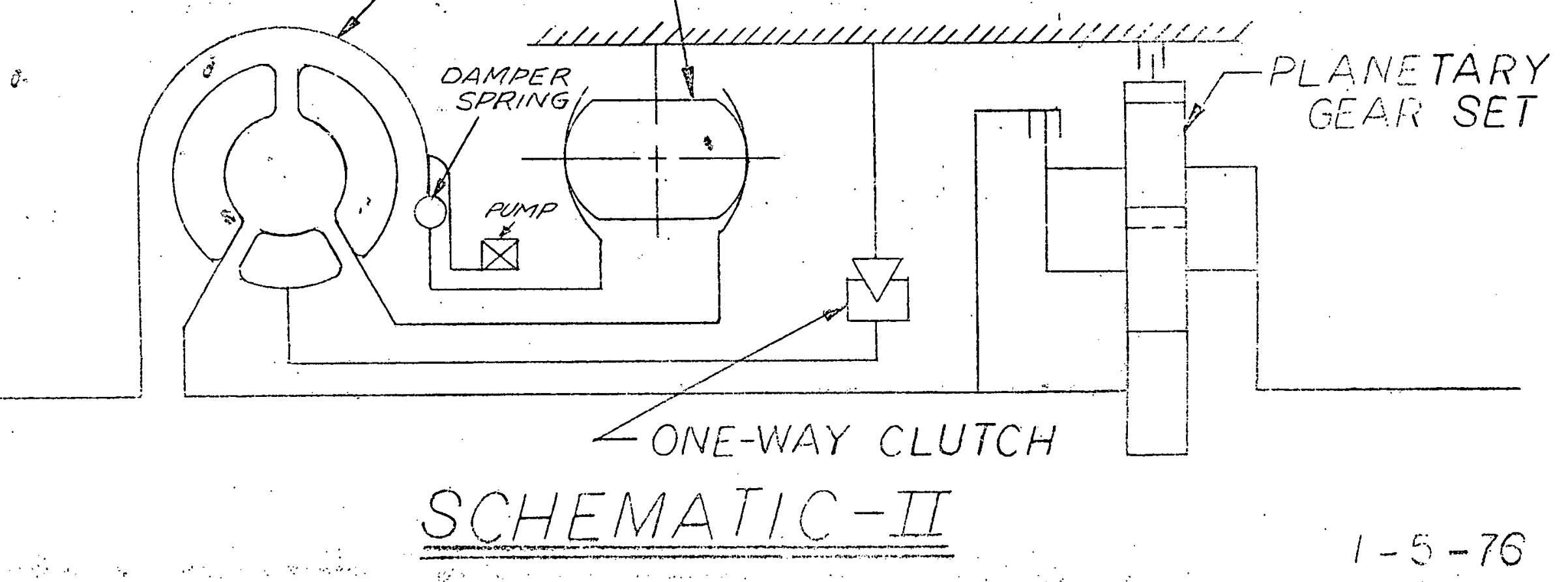




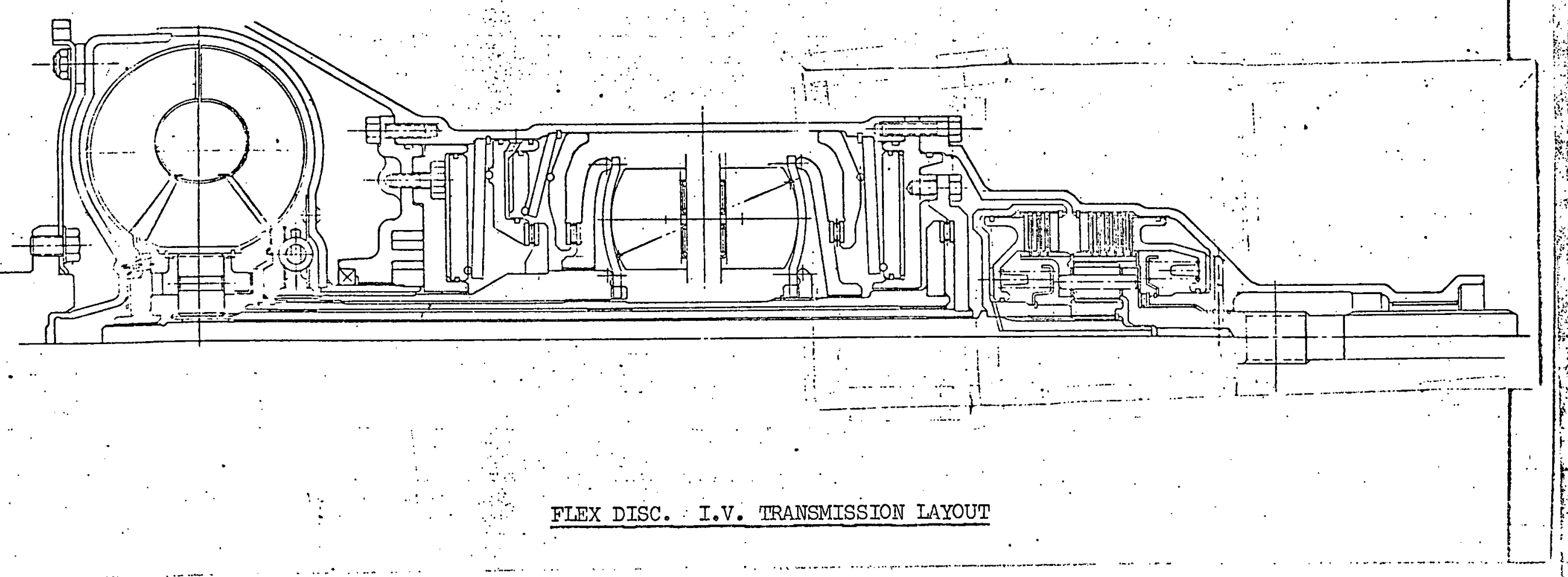




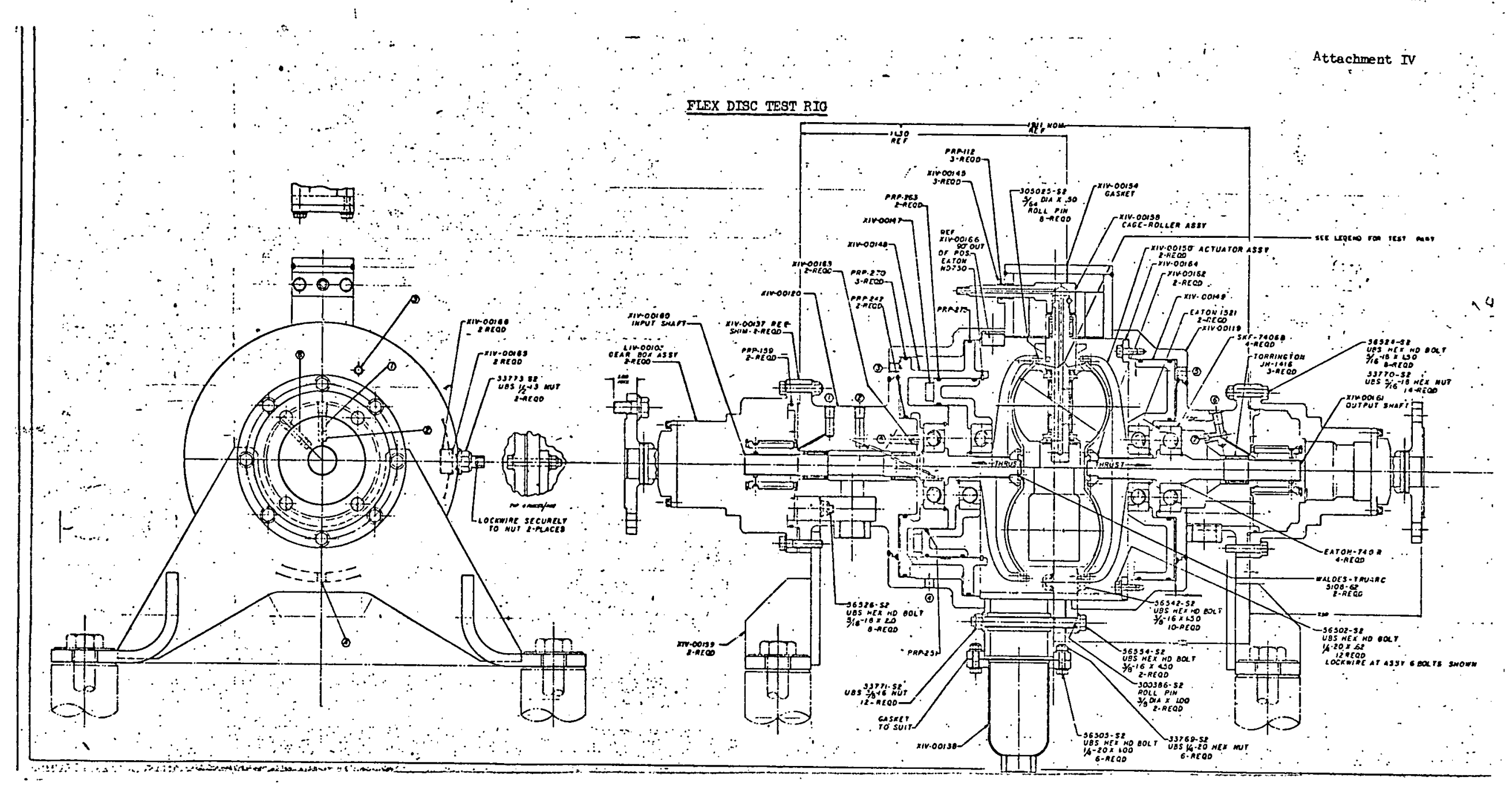




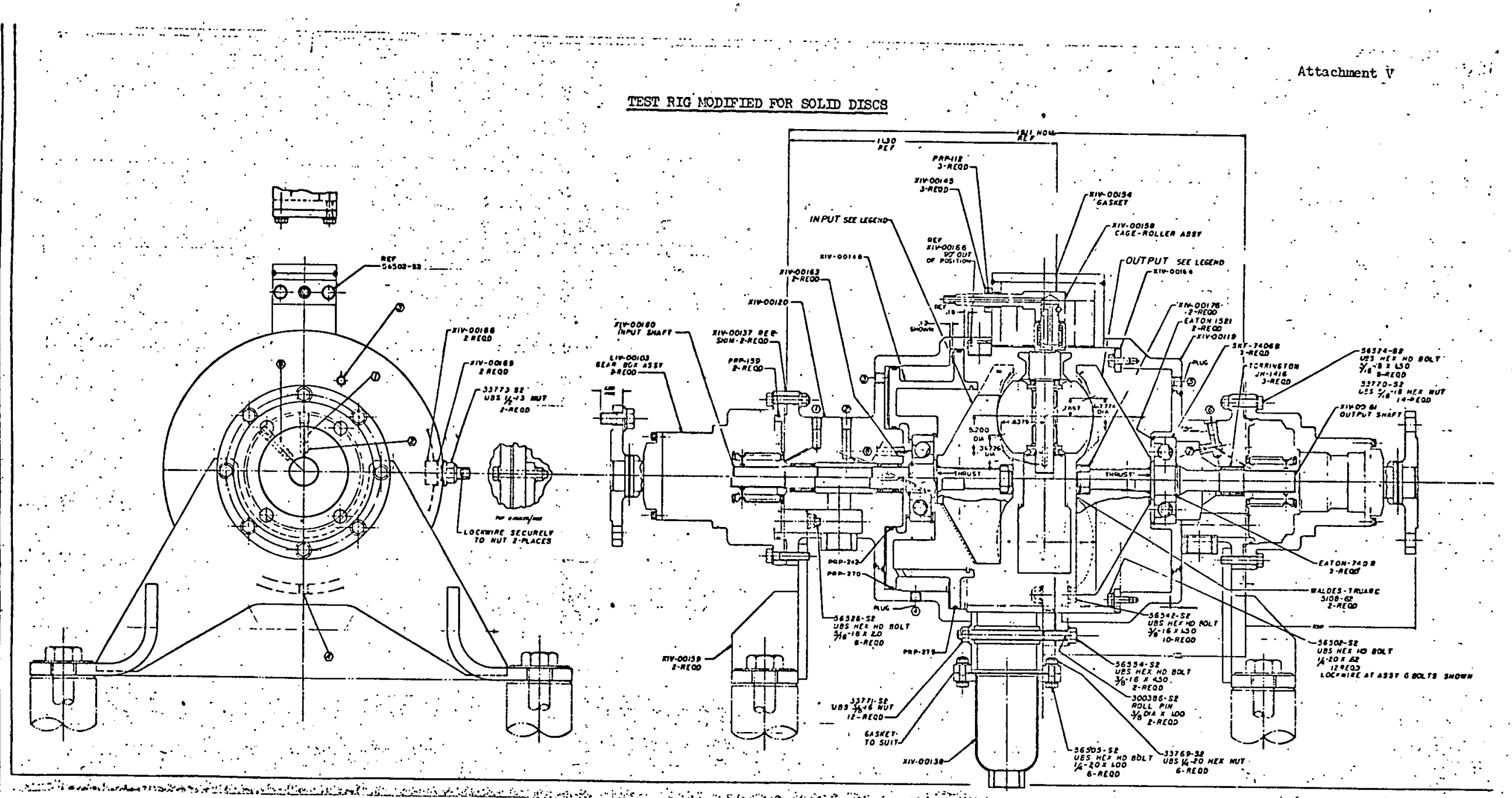

